\title{
Disseminated Cutaneous Sporotrichosis in an Immunosuppressed Patient
}

Paola Machado Gomes Esteves ${ }^{1}$, Beatriz Moritz Trope ${ }^{1}$, Marcella Gramigna Magalhaes Barbalho', Tyomi Akiti ${ }^{1}$ and Marcia Ramos-e-Silva ${ }^{1 *}$

${ }^{1}$ Sector of Dermatology and Post-Graduation Course - University Hospital and School of Medicine, Federal University of Rio de Janeiro, Brazil ${ }^{2}$ Mycologist, Mycology Laboratory, University Hospital and School of Medicine, Federal University of Rio de Janeiro

\begin{abstract}
The authors present a case of sporotrichosis, a systemic fungal infection frequently observed in Rio de Janeiro, where nowadays most cases are transmitted by cats. The disseminated cutaneous form, as seen in our patient, is rare and shows multiple cutaneous lesions. This form is almost always associated with immunosuppression, as the case we present, who was diagnosed as HIV+ during the diagnostic evaluation of the mycosis.
\end{abstract}

Keywords: Sporotrichosis; Sporothrix; Immunosuppression

\section{Introduction}

The case presented exemplifies disseminated cutaneous sporotrichosis, affecting an immunocompromised individual.

This disease is a subacute or chronic infection caused by the Sporothrix complex [1,2]. It is a primary cutaneous infection with different clinical forms: disseminated by lymphatic vessels, the most frequent, localized cutaneous, disseminated cutaneous and rarely extracutaneous form. The cutaneous disseminated and systemic forms of sporotrichosis are considered very severe opportunistic infections and usually occur in immunodepressed patients [2]. It is endemic in Rio de Janeiro, Brazil, where transmitted mainly by traumatic skin inoculation, as can occur with owners and professionals leading with cats [3]. Several cases have been reported to be associated with HIV $[1,4]$.

\section{Case Report}

A 30-years-old black man presented ulcero-crusted disseminated cutaneous lesions associated to dysphagia for around three months. He referred loss of weight, odynophagia, productive cough and afternoon fever for the past six months. When asked, the patient stated he did not have any contact with animals, including cats, or worked with plants.

On examination, he showed ulcero-crusted round lesions. They were individualized, non-confluent affecting the face (Figure 1), upper and lower limbs, antero-posterior trunk (Figure 2) and nasal and oral mucosa. (Figure 3) The main differential diagnoses were: systemic mycosis, cutaneous tuberculosis, cytomegalovirosis, atypical

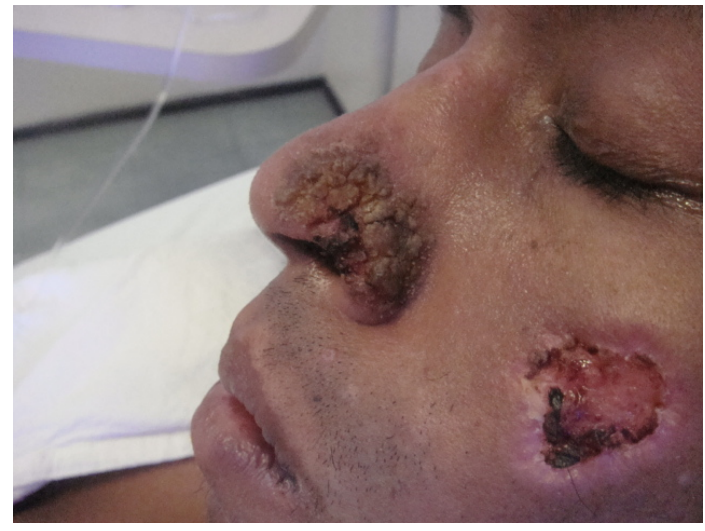

Figure 1: Lesions on the left side of the face.

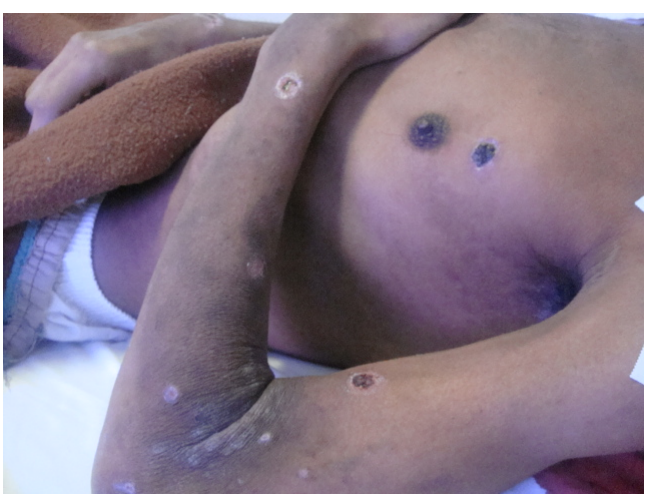

Figure 2: Lesions on the right side of the face.

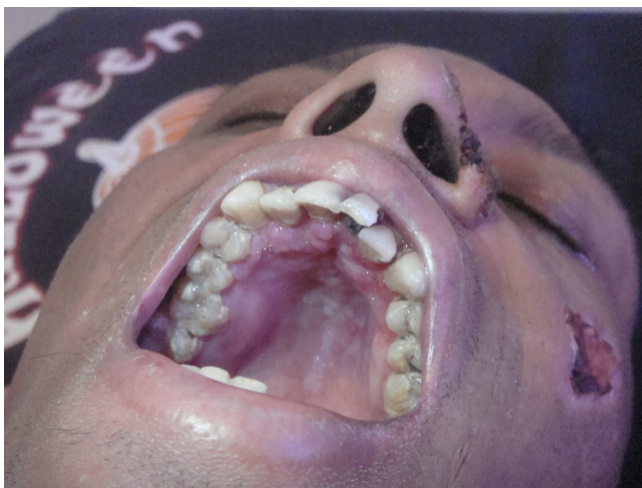

Figure 3: Lesions on the left arm and trunk.

*Corresponding author: Marcia Ramos-e-Silva, Sector of Dermatology and Post-Graduation Course - University Hospital and School of Medicine, Federa University of Rio de Janeiro, Rua Dona Mariana 143 / C-32, Botafogo 22280 020, Rio de Janeiro Brazil, Tel: 55-21-999852696; Fax: 55-21-22864632; E-mail: ramos.e.silva@dermato.med.br

Received June 20, 2014; Accepted September 20, 2014; Published September 29, 2014

Citation: Esteves PMG, Trope BM, Barbalho MGM, Akiti T, Ramos-e-Silva M (2014) Disseminated Cutaneous Sporotrichosis in an Immunosuppressed Patient. J AIDS Clin Res 5: 352. doi:10.4172/2155-6113.1000352

Copyright: (C) 2014 Esteves PMG, et al. This is an open-access article distributed under the terms of the Creative Commons Attribution License, which permits unrestricted use, distribution, and reproduction in any medium, provided the original author and source are credited. 
mycobacteriosis and leishmaniasis. The patient stayed in the in-patient clinic, where skin biopsy, radiological and laboratorial investigation were performed, which ruled out the most common opportunistic infections seen in Aids patients.

The laboratory exams showed that the patient was HIV positive (viral load: 76.023 copies, CD4: 114 cells $/ \mathrm{mm}^{3}$ ). Chest tomography revealed presence of opacity similar to dull glass and bronchial thickening. He had ulcerated esophagitis with negative biopsy for fungi, virus and bacteria in the digestive endoscopy, and negative induced sputum negative for fungi or BAAR.

Mycological exam of the fragment of one of the lesions of the left arm demonstrated growth of colonies of membranous aspect on agar Sabouraud. It was initially white, becoming black after a few days, and forming a halo in the form of a horseshoe (Figure 4). In micro culture, delicate conidiophores, thin, septated hypha and, in the extremity, conidia in an arrangement similar to a daisy (Figure 5), confirming the diagnosis of sporotrichosis.

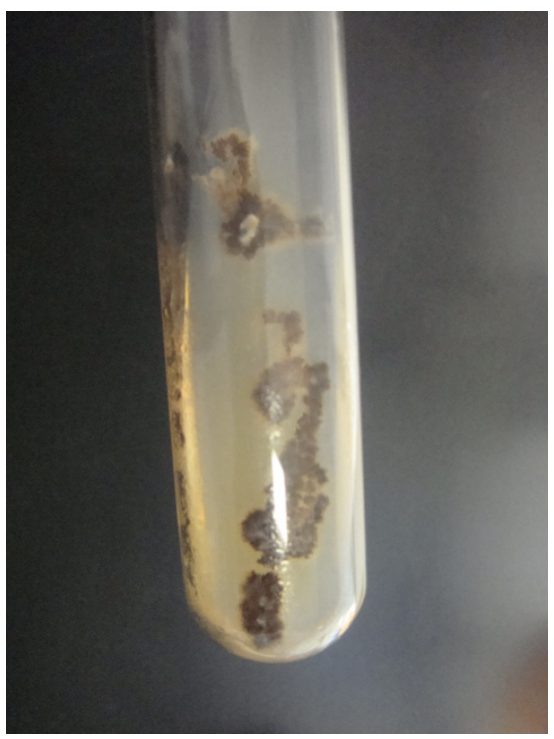

Figure 4: Lesions on the legs.

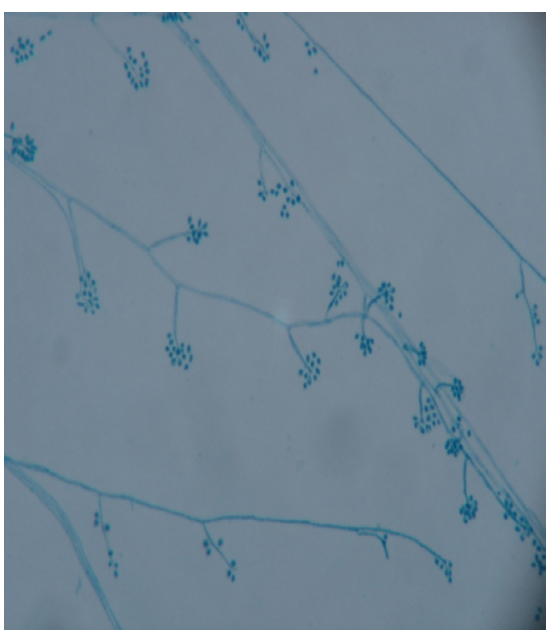

Figure 5: Lesions on palate.
Histopathological exam of the skin biopsy of a lesion of the left arm was inconclusive and showed hyperkeratosis, parakeratosis, acanthosis, vascular proliferation, fibrosis and perivascular mononuclear inflammatory; absence of granuloma, neoplasia or viral cytopatic effect. Grocott and PAS techniques did not show microorganisms.

Amphotericin B, $3 \mathrm{mg} / \mathrm{kg}$ per day, was initiated, but because of the toxicity of the drug it had to be discontinued. Itraconazol, $400 \mathrm{mg} /$ day, was given with clinical improvement of the patient. Maintenance of this dose is planned for at least 6 months.

\section{Discussion}

Sporotrichosis is a subcutaneous mycosis with sub-acute or chronic progression. It is caused by direct inoculation of a dimorphic fungus, one of the species of the Sporothrix complex, especially Sporothrix schenckii, through breakage of continuity of skin or mucosa $[1,5,6]$. More than 6 species have been identified in different locations of the globe by molecular techniques, such as $S$ schenckii sensu stricto, Sporothrix brasiliensis, Sporothrix globosa, Sporothrix mexicana, and Sporothrix albicans [7].

In the skin, lymphocutaneous, fixed and disseminated cutaneous forms can be clinically observed, with or without involvement of ocular, nasal and oral mucosa. Besides those, extracutaneous, pulmonary, osteoarticular, meningeal and generalized forms can be observed $[5,6]$.

In the city of Rio de Janeiro, Brazil, there has been an epidemic of sporotrichosis transmitted mainly by cats since 1997 [1,4,8,9]. Freitas et al. [4], studying 21 cases of sporotrichosis associated with HIV in Rio de Janeiro, found that the most frequent clinical presentation were lymphocutaneous (seven patients, 33.3\%), disseminated (seven patients, 33.3\%), disseminated cutaneous (five patients, 23.8\%), and fixed form (two patients, 9.5\%).

The form of presentation seen in our patient occurs in greater frequency in immunodepressed individuals, especially HIV positive patients, and result from fungal hematogenic dissemination from an initial inoculation site $[10,11]$. It is characterized clinically by disseminated, nodule-gummatous and frequently ulcerated lesions [5]. Treatment of choice is amphotericin B, but its use is often limited due to its high toxicity. Terbinafine, ketoconazol, itracanozol, fluconazol and saturated solution of potassium hydroxide can be used as alternative therapy, and among them itraconazol is the most effective [12-14].

\section{Conclusion}

It was found that the patient had a positive serology for HIV associated to the disseminated cutaneous form of sporotrichosis with nasal and oral mucosa involvement, as described in the literature.

\section{References}

1. Costa RO (2009) Micoses subcutâneas e sistêmicas. In: Ramos-e-Silva M Castro MCR. (Eds.), Fundamentos de Dermatologia. Rio de Janeiro: Atheneu 861-863.

2. Romero-Cabello R, Bonifaz A, Romero-Feregrino R, Sánchez CJ, Linares $Y$, et al. (2011) Disseminated sporotrichosis. BMJ Case Rep.

3. de Carvalho Aguinaga F, Trope BM, Fernandes NC, Engel DC, Ramos-E-Silva M (2014) Sporotrichosis with bone involvement: an alert to an occupational disease. Case Rep Dermatol 6: 114-118.

4. Freitas DF, de Siqueira Hoagland B, do Valle AC, Fraga BB, de Barros MB, et al. (2012) Sporotrichosis in HIV-infected patients: report of 21 cases of endemic sporotrichosis in Rio de Janeiro, Brazil. Med Mycol 50: 170-178.

5. Sampaio SA, Da Lacaz CS (1959) [Clinical and statistical studies on sporotrichosis in Sao Paulo (Brazil)]. Hautarzt 10: 490-493. 
Citation: Esteves PMG, Trope BM, Barbalho MGM, Akiti T, Ramos-e-Silva M (2014) Disseminated Cutaneous Sporotrichosis in an Immunosuppressed Patient. J AIDS Clin Res 5: 352. doi:10.4172/2155-6113.1000352

Page 3 of 3

6. Ramos-e-Silva M, Vasconcelos C, Carneiro S, Cestari T (2007) Sporotrichosis. Clin Dermatol 25: 181-187.

7. Vásquez-del-Mercado E, Arenas R, Padilla-Desgarenes C (2012) Sporotrichosis. Clin Dermatol 30: 437-443.

8. De Lima Barros MB, de Oliveira Schubach A, Galhardo MC, Schubach TM, dos Reis RS, et al. (2003) Sporotrichosis with widespread cutaneous lesions: report of 24 cases related to transmission by domestic cats in Rio de Janeiro, Brazil. Int J Dermatol 42: 677-681.

9. Galhardo MC, De Oliveira RM, Valle AC, Paes Rde A, Silvatavares PM, et al. (2008) Molecular epidemiology and antifungal susceptibility patterns of Sporothrix schenckii isolates from a cat-transmitted epidemic of sporotrichosis in Rio de Janeiro, Brazil. Med Mycol 46: 141-151.

10. Ware AJ, Cockerell CJ, Skiest DJ, Kussman HM (1999) Disseminated sporotrichosis with extensive cutaneous involvement in a patient with AIDS. $J$ Am Acad Dermatol 40: 350-355.

11. Morris-Jones R (2002) Sporotrichosis. Clin Exp Dermatol 27: 427-431.

12. Carvalho MT, de Castro AP, Baby C, Werner B, Filus Neto J, et al. (2002) Disseminated cutaneous sporotrichosis in a patient with AIDS: report of a case. Rev Soc Bras Med Trop 35: 655-659

13. Kauffman CA, Bustamante B, Chapman SW, Pappas PG; Infectious Diseases Society of America (2007) Clinical practice guidelines for the management of sporotrichosis: 2007 update by the Infectious Diseases Society of America. Clin Infect Dis 45: 1255-1265.

14. Ottonelli Stopiglia CD, Magagnin CM, Castrillón MR, Mendes SD, Heidrich $D$, et al. (2014) Antifungal susceptibilities and identification of species of the Sporothrix schenckii complex isolated in Brazil. Med Mycol 52: 56-64. 